\title{
OPTIMIZATION OF SORTING SYSTEMS IN DESTINATION DISTRIBUTION CENTERS OF BUSINESS-TO-CONSUMER COURIER COMPANIES
}

\author{
Hui Gao \\ Tongji University \\ School of Economics and Management, Tongji University, Shanghai \\ 200092, P.R.China \\ huigao1991@gmail.com \\ Xuping Wang \\ Dalian University of Technology \\ Faculty of Management and Economics, Dalian University of \\ Technology, Dalian 116024, P.R. China \\ School of Business, Dalian University of Technology, Panjin 124221, \\ P.R.China \\ wxp@dlut.edu.cn \\ Xiukun Chai \\ Dalian University of Technology \\ Faculty of Management and Economics, Dalian University of \\ Technology, Dalian 116024, P.R. China \\ chaixk@126.com \\ Hongtao Liu \\ Dalian University of Technology \\ Faculty of Management and Economics, Dalian University of \\ Technology, Dalian 116024, P. R. China \\ 201044140@dlut.edu.cn
}

\section{ABSTRACT}

We analyzed the workflow of sorting systems in destination distribution centers of current courier companies and identified problems. Subsequently, two points of view were put forth regarding the optimization of sorting systems: the first is to apply radio frequency identification technology (RFID) to sorting systems and vertically optimize the sorting process inside the courier companies; the second is to implement a sharing mechanism for sorting systems to integrate sorting systems of courier 
companies horizontally. Further, data regarding manual sorting systems and automated assembly line sorting systems were compared through simulation. The results show that when actual daily processing capacity is higher than the processing capacity at the inflection point, automatic assembly line sorting systems are more economical and efficient than manual sorting systems.

Keywords: Automated Assembly Line Sorting, Radio Frequency Identification Technology, Simulation

\section{INTRODUCTION}

Business-to-customer e-commerce has achieved explosive growth in China. Consumer delivery demands reflect multi-variety, small-volume and multiple batch characteristics. Customers are mostly dispersed and the products they purchase are generally small items with low prices. As such, logistics costs accounts for a larger proportion of the expenditure. The express-delivery industry in China consists of three main types: state-owned courier companies like China Railway Express and EMS; private courier companies like Shun Feng Express and Shen Tong Express; and international companies like UPS and FedEx.

In the business-to-customer space, e-commerce places a higher emphasis on the user experience. As such, consumer requirements in terms of logistics are more stringent than customer-to-customer online shops. E-commerce that has brought about significant courier companies profits and they are now beginning to build their own logistics system due to dissatisfaction with third-party distribution platforms, such as Jingdong Mall, Taobao, Suning and others. Although domestic private courier companies are growing rapidly, future development is still worrying. Sorting, as the middle part of logistics, is the core part of the system. Improving the efficiency of sorting systems is key to enhancing the efficiency of distribution and compressing logistics costs. This paper aims to propose an express automatic sorting system with the support of the radio frequency identification technology and use of an automated assembly line instead of manual sorting to improve efficiency and reduce error rates.

There is much literature related to warehouse selection and sorting systems. The definition of a selection system is to remove a small part of the cargo from the storage system to meet the demands of an individual customer $^{1}$. A selection system has a higher intensity than manual labor. Manual labor affects both the total logistics cost and the service level of 
logistics $^{2}$. In most cases, the cost related to the selection activities accounts for more than half of the total storage cost ${ }^{3,4}$.

Different from a warehouse selection system, express items reach the sorting area directly after arriving at the distribution center and do not need to be stored at a distribution center. The operation process of a distribution center includes sorting, packaging, distribution and so on. But in the current situation, the labor intensity of manual sorting is also high, which increases the logistics cost and affects the level of logistics service. With the development of identification technology, radio frequency identification technology has become a key technology to improve the efficiency and effectiveness of logistics and supply chain management. Radio frequency identification technology can use a radio frequency signal to identify, classify and manage logistics and information flow without human intervention, and thus avoids human errors to a large extent ${ }^{5}$.

Fosso Wamba et al. ${ }^{6}$ analyzed the impact of the integration of radio frequency identification technology and electronic product code network for mobile commerce and e-business. He pointed out that using radio frequency identification technology in the supply chain can achieve automatic operation and a high level of information sharing and strengthen the synchronization of information to improve the business processes. S. Fosso Wamba et al. $^{7}$ show the application of radio frequency identification technology in a warehouse selection and shipping process of third-party logistics companies. They said that radio frequency identification technology can support business process reengineering, improve the data quality and timeliness of data collection, and the synchronization of data and information sharing. Huang et al. ${ }^{8}$ point out that using radio frequency identification automated a data collection system and replaced a manual data acquisition system, thus achieving timely information exchange for multiple decision support systems.

Most of the literature associated with radio frequency identification technology describes the advantage of radio frequency identification technology in information sharing and data collection in a warehouse selection system. Actually, with the characteristics of non-contact identification and high reading speed, radio frequency identification technology will also play a crucial role in the courier companies' sorting systems. In the process of sorting, radio frequency identification technology can quickly obtain information from express items and achieve automatic sorting of express items through the combination of both a computer control system and mechanical transmission system. This paper discusses the use of radio frequency identification technology to redesign the sorting process of courier companies and further contrast between manual sorting and 
automated assembly line sorting based on radio frequency identification technology that is reflected in efficiency, cost and other indicators. The second part of the paper analyzes the workflow of a courier company's destination distribution center and points out the problems in the process of sorting. The third part proposes two points of view on the optimization of sorting systems for a courier company. The first is to apply radio frequency identification technology to sorting systems, the second is to propose a sharing mechanism for sorting systems. The fourth part summarizes the contributions of this paper and implications for courier company managers based on the paper's conclusions. Lastly, further research directions are presented.

\section{WORKFLOW ANALYSIS OF DISTRIBUTION CENTER IN COURIER COMPANIES}

Figure 1 shows the basic process of online shopping in an e-commerce environment. E-commerce companies select and sort out express items from warehouses based on customer orders and deliver the express items to third-party logistics companies. The third-party logistics company will then transport the express items to the destination distribution center. The distribution center will arrange vehicles and deliver express items to the online shopping customers. This paper focuses on the optimization of the sorting process at the destination distribution center of third-party logistics companies.

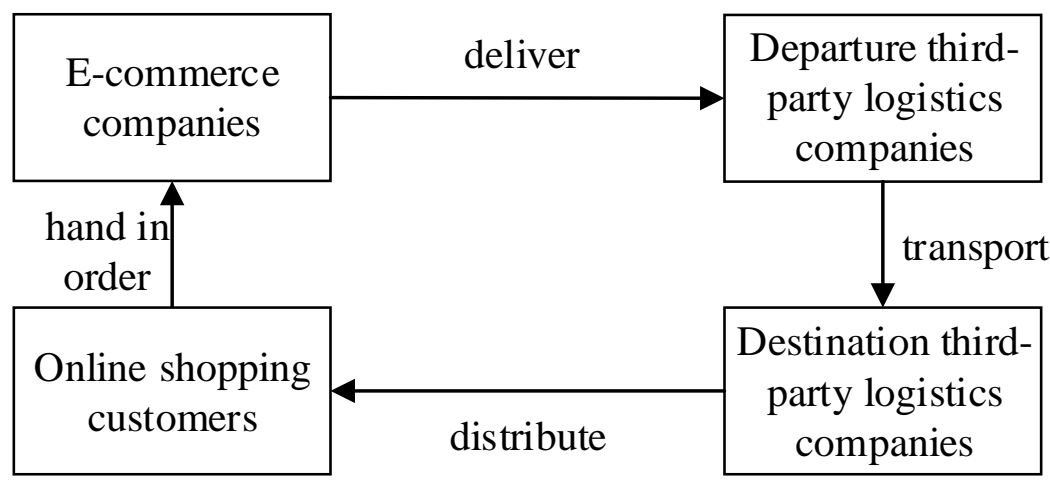

Figure 1. The basic process of online shopping in an e-commerce environment

The operating process of destination third-party logistics companies is as follows: the destination distribution center of the third-party logistics company receives express items from the airport, train or car and transports the express items to a temporary storage area or sorting area by trolley or 
conveyor. Then sorting systems start to operate. Workers sort out the express items and put them in corresponding turnover boxes according to customer order information. After sorting, the turnover boxes are shipped to a temporary storage area and workers will check the orders. Once verified, the express items in the turnover boxes will be properly packaged and delivered on time. Drivers will transport express items to certain distribution points. The delivery staff will deliver the express items to the customers and complete the final recipient signature paperwork.

Currently, the destination distribution centers of most domestic third-party logistics companies are still labor-intensive, especially for the process of sorting. Manual sorting is time consuming with a high error rate, high labor cost, low turnover speed and also prone to problems such as omission, fault and damage. Some sorting centers of courier companies have adopted the following methods: express items are transported from vehicles to the conveyor belt with workers standing on both sides. The information pasted on the package is identified visually by staff. Staff will then take the express items from the conveyor belt according to the address or the area code on the waybill. Express items that belong to the same area are packed and put into transport vehicles. Since workers still sort by hand in most distribution centers, the logistics information of the express items cannot be fed back to the e-commerce companies and customers in real time. Thus, there is a lag in providing logistics information for the express items.

Through analysis of current sorting centers of courier companies in China, we can see that it is critical to improve the level of automation and information in order to enhance distribution efficiency. The informatization of sorting centers depends on automatically reading the information of the express items through radio frequency identification technology and sharing information with multi-party logistics through computers connected to the network. The automation relies on an automated assembly line operated by an automatic control system.

\section{OPTIMIZATION DESIGN OF SORTING SYSTEMS}

\section{IN COURIER COMPANIES}

The application of radio frequency identification technology and automated assembly line operation can greatly reduce labor intensity, enhance work efficiency and effectively control breakage rate, loss rate and delay rate that affects the quality of current logistics service. The optimization design of sorting systems needs to simplify the processes of sorting inside the company longitudinally. Meanwhile, cooperation with 
other companies and horizontal business integration can be achieved through a sharing mechanism for sorting systems.

\subsection{Workflow Design of Sorting Systems Based on Radio Frequency Identification}

The express items received by courier companies can be divided into letters and parcels. Companies need to introduce different sorting machines for these two different types of express items. In the current infrastructure, express items are mostly distinguished by a bar code that contains the waybill number, origin, destination and other information. All the information is read by a scanner. Therefore, to achieve an optimization of sorting systems, we need to get start with the bar code and scanning equipment to obtain information.

Applying radio frequency identification technology to sorting systems can greatly improve sorting efficiency. Companies need to install a wireless end reader on the conveyor belt in a sorting area in order to scan and obtain information from express items. The wireless end reader also needs to be connected with the automatic transmission system to achieve information sharing and allocation of express items.

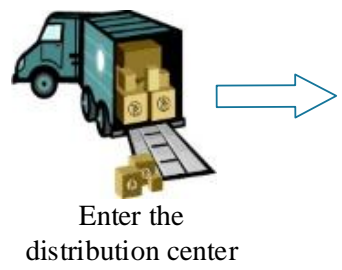

distribution center
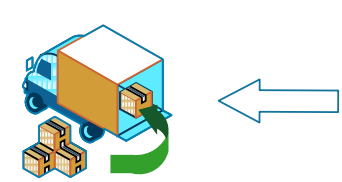

Enter the delivery area

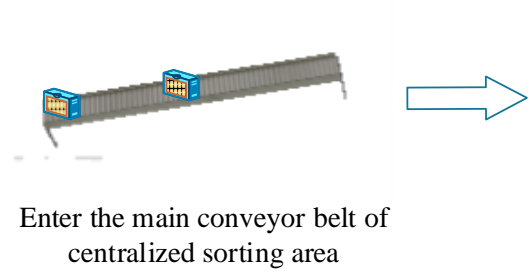

Scan express items information by RFID

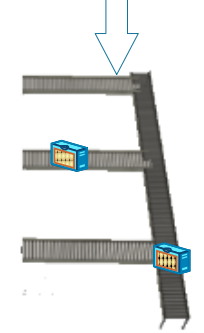

Enter the secondary sorting point

Figure 2. Workflow design of sorting systems

The combination of radio frequency identification technology, computer information control systems and mechanical transmission systems can realize one-stop automatic information reading and cargo sorting from the entrance to every sorting point. Today, automation plays an important role in dealing with express items. This can automatically classify and also achieve automated movement in sorting centers by reading the address ${ }^{9}$. 
Compared with the hand-held bar code scanners, radio frequency identification technology can shorten sorting time and simplify the sorting process, and also ensure the integrity of express item packaging. Applying the features of radio frequency identification technology is superior to traditional bar code scanning technology for sorting systems that handle express items and can improve the efficiency of the sorting process, shorten the response time of orders, and achieve rapid sorting with high-volume.

The specific workflow in sorting centers can be designed as follows (Figure 2):

(1) Enter centralized sorting area

Once arriving at the destination distribution center, express items are sent to the main conveyor belt for sorting to delivery areas. Express items will move with the belt and come close to the wireless end reader on the conveyor belt. The scanner automatically scans labels of express items and uploads location information to the computer control system. The mechanical transmission system that is controlled by the program will then complete a lane change to automatically direct express items to the corresponding sorting area.

\section{(2) Enter secondary sorting point}

After express items reach the corresponding sorting area, a wireless end reader will scan the tag and upload the information of the secondary address of express items to the computer control system. The mechanical transmission device then adjusts lanes so that the express items flow to the sub-sorting point.

\section{(3) Enter review area and packaging area}

Computers at every sorting port are connected with a printer and wireless end reader on the main conveyor belt. When express items flow to the exit of every sorting area, the wireless end reader set on the lintel of the exit will scan the information of the passing express items again. Then workers will check the information of express items that has already been scanned with customer's order. If there is no mistake, express items will be packaged and sent to the conveyor again.

(4) Enter delivery area

Conveyors will deliver packaged express items to the conveyor belt of delivery areas. The belt can go up and down, stretch out and back and directly extend into the delivery trucks. Once express items are loaded on trucks, the preparatory work of delivery finishes.

For domestic private courier companies, using radio frequency identification technology to automatically identify express item information and distinguish express items according to address can greatly improve the 
sorting efficiency. However, an automatic sorting system has a high disposable input cost and investment risk. Therefore, courier companies need to carefully consideration the long-term use of sorting centers, the payback period of equipment, and the handling capacity of distribution centers.

\subsection{Simulation of Sorting Systems in a Sharing Mechanism}

According to the survey, large logistics companies, such as SF Express, have established automated assembly line in sorting centers. The automated assembly line works 24 hours without downtime and the daily sorting capacity of express items can reach hundreds of thousands. In contrast, small-scale private courier companies combine a storefront with sorting centers and normal working hours are from 7:00 a.m. to 21:00 p.m. During holidays like Spring Festival, they have to work much longer hours. Nowadays, the industry is highly competitive. For small and medium courier companies, it is particularly important to introduce a sharing mechanism for sorting systems to achieve an integration of resources and complementarity advantages. Sorting, as a key process in distribution centers, has the highest input costs and consumes the resources. Small- and medium-sized courier companies can consider outsourcing their sorting process to the forth-party logistics companies or courier companies that have advanced sorting systems in order to achieve an efficient use of resources and help reduce turnaround costs and disposable input costs.

A simulation based on queuing theory helps to properly plan the scale of an automated assembly line in sorting systems and learn more about the daily volume of business, the sorting efficiency, the loading rate of the automated assembly line and other indexes under sharing systems. It is a powerful decision-making tool for companies. In sorting systems, we are concerned about the following indexes:

(1) Average number of express items in the waiting line $\overline{L_{q}}$

(2) Average time spent in the waiting line $\overline{\mathrm{W}_{\mathrm{q}}}$

(3) Average scheduled utilization $\rho$.

\subsubsection{Assumptions of express items sorting systems model}

A computer simulation was used to model and simulate the actual situation of systems and study existing or under-designed systems. Therefore, we need to assume, analyze and summarize models. The key consideration is to reflect the actual situation through reasonable assumptions. We made the following assumptions regarding express item sorting systems according to three elements of queuing theory: 


\section{(1) Input process}

The service object is express items in a sorting center. The arrival of express items is random and the number of potential express items is assumed to be infinite. The arrival of express items will follow a Poisson distribution. The average express items arrival rate will be denoted by the symbol $\lambda$ which means the average number of express items arriving in one unit time.

\section{(2) Queuing discipline}

The queue discipline is of a first come first served (FCFS) nature. If all servers are busy when an express item arrives, the arriving express item must join the single queue. If one server is idle while all the other servers are busy at the time an express item arrives, this idle server must serve this newly arrived express item immediately. The express item that has waited for the longest time will be the next one to receive service from this idle server.

\section{(3) Service process}

The service process will follow a negative exponential distribution where the service time will be symbolized by the constant average rate $\mu$ which means the average number of express items served in one unit time. The number of available servers in the service facility will be equal to the positive integer value denoted by the letter $\mathrm{c}(0<\mathrm{c}<\infty)$. Each of the $\mathrm{c}$ servers follows the identical negative exponential distribution given in the service process.

In summary, the sorting system is a queuing system of $[M / M / C]:[\infty / \infty / F C F$.

\subsubsection{Queuing model of express items in sorting systems}

There is only one queue in sorting systems. Therefore arrived express items only need to wait for sorting in the queue in the order of arrival. $[M / M / C]:[\infty / \infty / F C F S]$ The queuing model is shown in Figure 3:

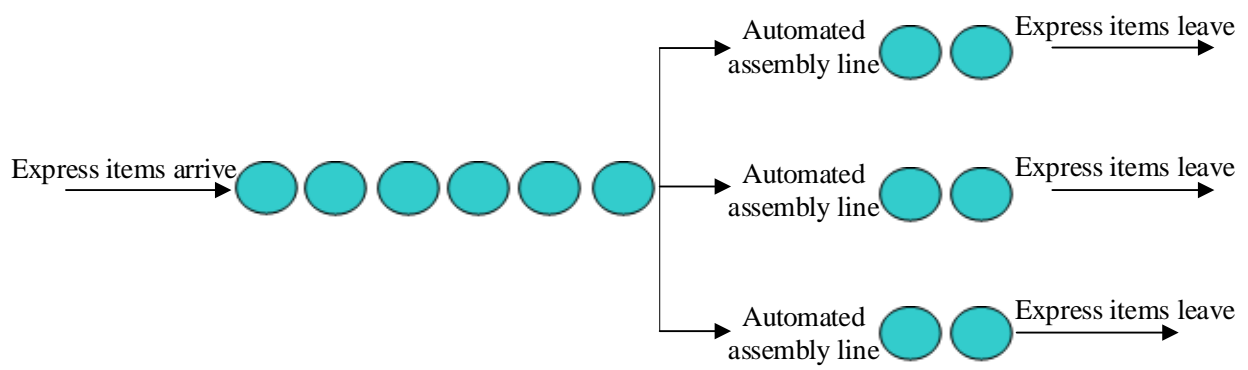

Figure 3. Queuing model 
The average scheduled utilization is denoted by the symbol $\rho$. The server utilization ration of each server is denoted by the symbol $\rho_{\mathrm{c}}$. The average number of express items in the waiting line is denoted by $\overline{L_{\mathrm{q}}} \cdot \overline{\mathrm{W}_{\mathrm{q}}}$ denotes average time spent in the waiting line. $P_{0}$ denotes probability of finding zero express items in the system. $P_{0}$ is defined as $P_{0}=\left[\sum_{\mathrm{j}=0}^{\mathrm{c}-1} \frac{\lambda^{\mathrm{j}}}{\mu j !}+\frac{\lambda^{c}}{\mu c !(1-\rho / \mathrm{c})}\right]^{-1} 10$.

Operation indexes of $[M / M / C]$ : $[\infty / \infty / F C F S]$ are as follows ${ }^{10 .}$

$$
\left\{\begin{array}{l}
\overline{W_{\mathrm{p}}}=\frac{\rho^{\mathrm{c}} P_{\mathrm{o}}}{\mathrm{c} !(1-\rho / \mathrm{c})^{2} \mathrm{c} \mu} \\
\overline{L_{\mathrm{p}}}=\lambda \overline{W_{\mathrm{q}}} \\
\rho=\frac{\lambda}{\mu}
\end{array}\right.
$$

3.2.3 Sorting systems simulation based on ARENA simulation software

ARENA is developed by Rockwell Software Inc., and it is used by the large community of system modelers ${ }^{11}$. ARENA software is based on the SIMAN simulation language and can simulate manufacturing, supply chain management, logistics, sorting and other processes ${ }^{12}$. G.E. Vieirae ${ }^{13}$ established an ARENA simulation model to perform detailed studies on the bullwhip effect in supply chains, caused by the demand variation from point-of-sales to suppliers. A.P. Iannoni and R. Morabito ${ }^{14}$ applied ARENA simulation software to study truck waiting time in various queues in the reception area of a sugarcane plant. This paper simulates both manual sorting and automated assembly line sorting processes.

\section{(1) Establish simulation model}

The simulation model for express sorting systems in an ARENA simulation environment is shown in Figure 4. Firstly, express items are sent to sorting centers and wait to be serviced. The discipline of the sorting center is first come first served. When a package is the earliest arrived express item, the express item will be placed on the conveyor belt to be sorted. After sorting, it will leave. 


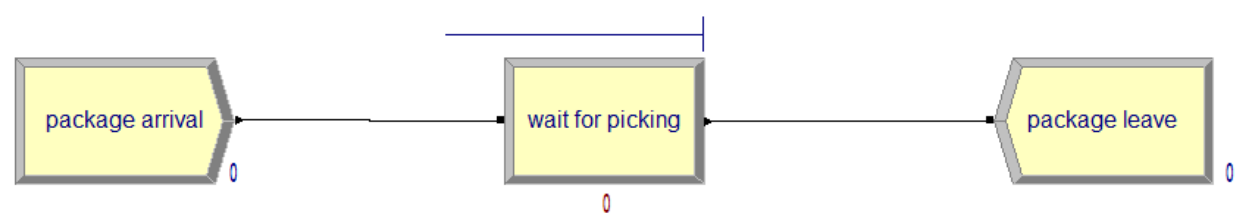

Figure 4. Model in the ARENA simulation environment

(2) Describe the basic simulation data

After researching courier company systems, we assumed that the annual cost of each automated assembly line sorting is 1 million / bar and there are 350 working days per year. The working hours of an automated assembly line is 24 hours per day. The working hours of manual sorting is 10 hours per day. Labor cost is set at 200 yuan per person per day. The automated assembly line sorting follows negative exponential distribution with the average service rate of $\mu=4$ pieces/min and manual sorting follows negative exponential distribution with the average service rate of $\mu$ $=1 / 3$ pieces $/ \mathrm{min}$.

(3) Conduct the data experiment

We take one year as a cycle and established a simulation model for both manual sorting and automated assembly line sorting processes. We input work hours and the daily number of express items at 1000, 2000, 3000, $4000,5000,6000,7000,8000$, and 9000. At the same time, we defined the arrival of express items as following a Poisson distribution. Then we ran the model 100 times and acquired the average arrival rate $\lambda$ in each situation. After that, we input the value of average service rate $\mu$, working hours and the average arrival rate $\lambda$ into the two simulation models. We set a different number of resources (the number of automated assembly lines or workers) and ran the two simulation models. The results contain the average number of express items in the waiting line $\overline{L_{\mathrm{q}}}$, the average time spent in the waiting line $\overline{\mathrm{W}_{\mathrm{q}}}$ and the average scheduled utilization $\rho$.

(4) Simulation analysis

The experiment was based on the calculation formula of

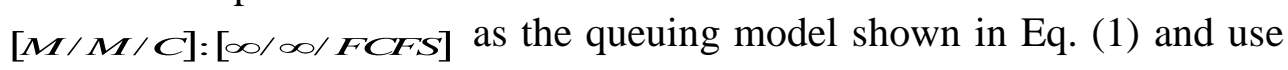
ARENA software to calculate the value of each operation index. Table 1 and Table 2 list the average number of express items in the waiting line $\overline{L_{\mathrm{q}}}$, 
the average time spent in the waiting line $\overline{\mathrm{W}_{\mathrm{q}}}$ and the average scheduled utilization $\rho$ when the daily number of express items were 1000, 2000, $3000,4000,5000,6000,7000,8000$ and 9000. In addition, we selected the least number of resources that can just finish sorting tasks as the number of resources. Annual cost was equal to the number of resources multiplied by the annual unit cost.

Table 1. Manual sorting simulation results

\begin{tabular}{ccccccc}
\hline $\begin{array}{c}\text { Daily } \\
\text { number of } \\
\text { express } \\
\text { items }\end{array}$ & $1 / \lambda$ & $\begin{array}{c}\overline{L_{\mathrm{q}}} / \\
\text { piece }\end{array}$ & $\begin{array}{c}\overline{\mathrm{W}_{\mathrm{q}}} \\
\mathrm{min}\end{array}$ & $\begin{array}{c}\text { Average } \\
\text { scheduled } \\
\text { utilization } \\
\rho\end{array}$ & $\begin{array}{c}\text { The } \\
\text { number of } \\
\text { resources }\end{array}$ & $\begin{array}{c}\text { Annual } \\
\text { cost/ } \\
1000 \text { yuan }\end{array}$ \\
\hline 1000 & 0.6 & 23.2 & 13.79 & $96.34 \%$ & 5 & 35 \\
2000 & 0.3 & 32.6 & 9.72 & $98.61 \%$ & 10 & 70 \\
3000 & 0.2 & 27.7 & 5.45 & $95.82 \%$ & 16 & 112 \\
4000 & 0.15 & 29 & 4.34 & $98.73 \%$ & 20 & 140 \\
5000 & 0.12 & 29.3 & 3.58 & $98.19 \%$ & 27 & 189 \\
6000 & 0.1 & 15.3 & 1.57 & $95.34 \%$ & 31 & 217 \\
7000 & 0.086 & 12.05 & 1.05 & $95.51 \%$ & 36 & 252 \\
8000 & 0.075 & 28.2 & 2.14 & $97.51 \%$ & 41 & 287 \\
9000 & 0.067 & 13.7 & 0.94 & $97.00 \%$ & 45 & 315 \\
\hline
\end{tabular}

Table 2. Automated assembly line sorting simulation results

\begin{tabular}{ccccccc}
\hline $\begin{array}{c}\text { Daily } \\
\text { number of } \\
\text { express } \\
\text { items }\end{array}$ & $1 / \lambda$ & $\begin{array}{c}\overline{L_{\mathrm{q}}} / \\
\text { piece }\end{array}$ & $\begin{array}{c}\overline{\mathrm{W}_{\mathrm{q}}} \\
\mathrm{min}\end{array}$ & $\begin{array}{c}\text { Average } \\
\text { scheduled } \\
\text { utilization } \\
\rho\end{array}$ & $\begin{array}{c}\text { The } \\
\text { number of } \\
\text { resources }\end{array}$ & $\begin{array}{c}\text { Annual } \\
\text { cost/ } \\
1000 \text { yuan }\end{array}$ \\
\hline 1000 & 1.44 & 0.03 & 0.05 & $17.08 \%$ & 1 & 100 \\
2000 & 0.72 & 0.18 & 0.13 & $34.43 \%$ & 1 & 100 \\
3000 & 0.48 & 0.57 & 0.28 & $52.07 \%$ & 1 & 100 \\
4000 & 0.36 & 1.61 & 0.58 & $69.75 \%$ & 1 & 100 \\
5000 & 0.28 & 6.5 & 1.86 & $87.40 \%$ & 1 & 100 \\
6000 & 0.24 & 0.39 & 0.09 & $51.61 \%$ & 2 & 200 \\
7000 & 0.21 & 0.62 & 0.13 & $58.72 \%$ & 2 & 200 \\
8000 & 0.18 & 1.33 & 0.24 & $69.60 \%$ & 2 & 200 \\
9000 & 0.16 & 2.4 & 0.39 & $77.24 \%$ & 3 & 300 \\
\hline
\end{tabular}




\subsubsection{Results}

Four findings were found after analysis of the data from Table 1 and Table 2.

Finding 1: When the actual daily processing capacity is higher than the processing capacity at the inflection point, automatic assembly line sorting systems are more economical than manual sorting systems.

We compared the sorting costs of automated assembly line sorting and manual sorting for several different daily number of express items and produced the line chart shown in Figure 5. When the daily number of express items reached a certain value between 2000 pieces and 3000 pieces, automated assembly line sorting had the same cost as manual sorting. When the daily number of express items was less than 2000 pieces, automated assembly line sorting had higher costs than manual sorting. When the daily number of express items was more than or equal to 3000 pieces, automated assembly line sorting had lower costs than manual sorting.

Therefore, companies need to decide whether to use automated assembly line sorting or manual sorting according to the daily number of express items. From the result of the simulation, companies should hire workers when the daily number of express items is less than 2000 pieces. Meanwhile, companies should consider installation of an automated assembly line once the daily number of express items is more than 3000 pieces.

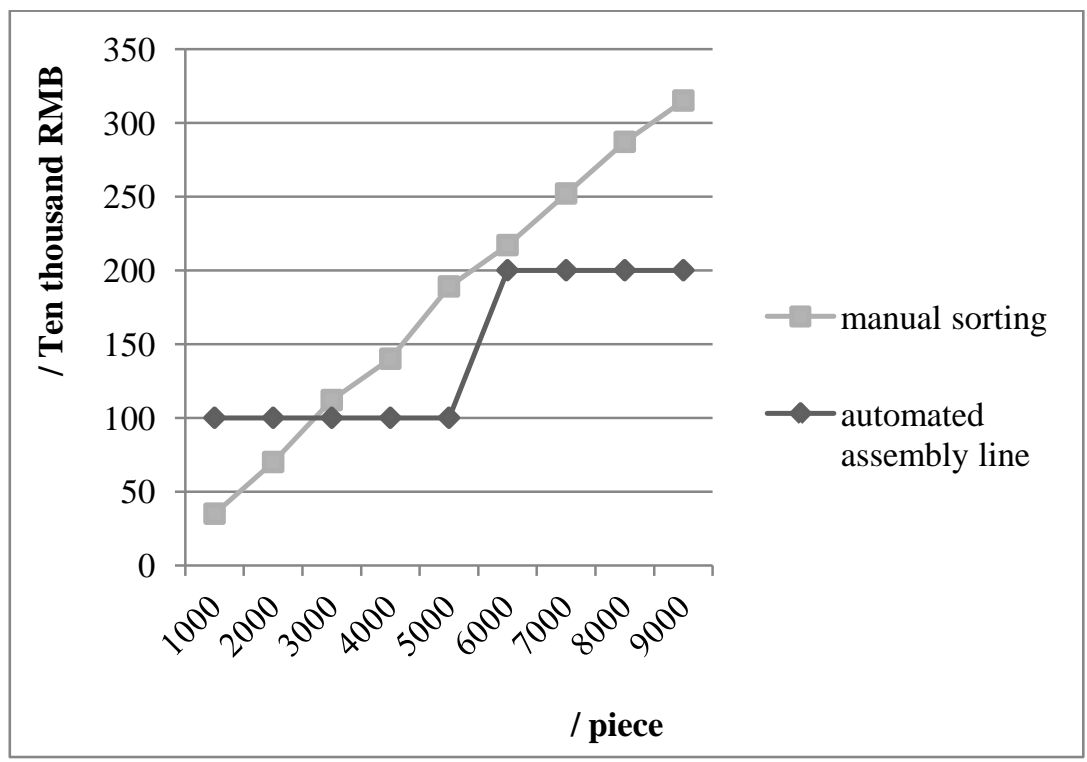

Figure 5. Annual costs between automated assembly line and manual sorting 
When the daily number of express items is more than 3000 pieces, companies need to add a new automated assembly line to complete the sorting task. Therefore, fixed costs will suddenly increase at this point. However, the cost of automated assembly line sorting is still lower than that of manual sorting and the advantage of cost reduction in automated assembly line sorting is further reflected with an increase of the daily number of express items.

Finding 2: The average number of express items in the waiting line in automated assembly line is at least 10 express items shorter than that in manual sorting.

Figure 6 shows that the average number of express items in the waiting line in an automated assembly line is at least 10 express items shorter than that in manual sorting with various different daily numbers of express items. And the average time spent in the waiting line in sorting systems is less than that in manual sorting. The reduction of average waiting number and waiting time in automated assembly line sorting improves turnover ratio and sorting efficiency of express items in sorting systems.

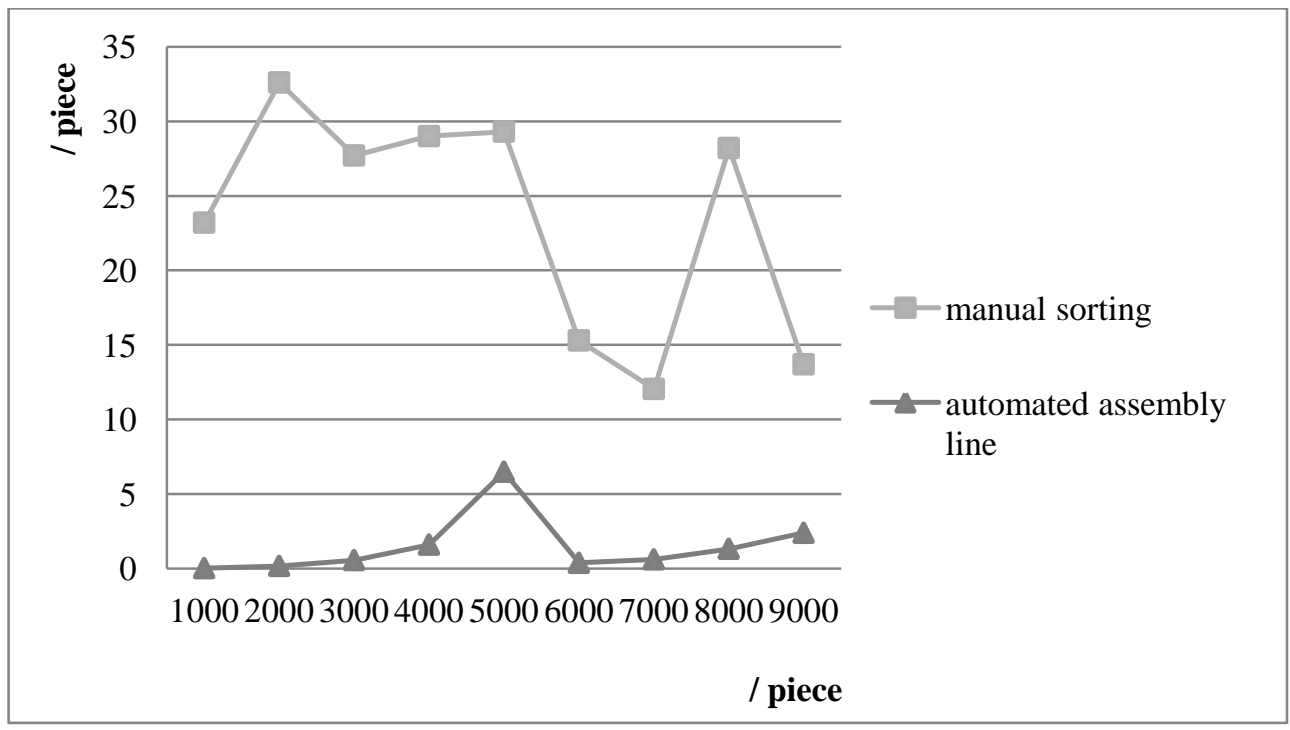

Figure 6. Average number of express items in the waiting line between automated assembly line sorting and manual sorting

Finding 3: When annual costs per automated assembly line fluctuate, the daily number of express items in the inflection point will change.

In this simulation, we assumed that annual costs increased by one million yuan when adding a new automated assembly line. At this time, the costs of automated assembly line sorting are equal to that of manual sorting 
when the daily number of express items is close to 3000 pieces. Companies with more than 3000 pieces in the daily number of express items can consider using automated assembly line sorting. Considering economy of scale and maintenance costs of purchasing equipment, we need to figure out the daily number of express items at the inflection point when the annual costs of adding an new assembly line are 1.2 million and 0.7 million.

When the annual costs of one automated assembly line is 1.2 million, the daily number of express items at the inflection point is a certain value between 3000 and 4000 pieces. Once the daily number of express items is more than 4000 pieces, automated assembly line sorting can be more economical.

When the annual costs of one automated assembly line is 0.7 million, the daily number of express items at the inflection point is 2000 pieces. When the number is more than 2000 , automated assembly line sorting costs are less than manual sorting.

Finding 4: When the number of automated assembly line is constant, the resource utilization of automated assembly line sorting increases along with an increase of the daily number of express items.

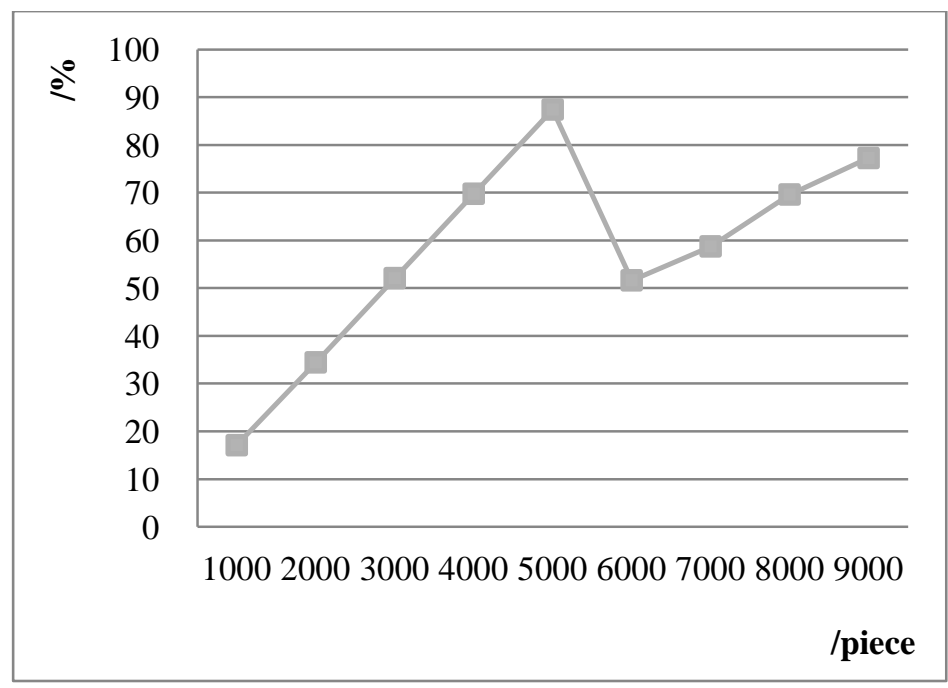

Figure 7. Variation trend of resource utilization of automated assembly line sorting

When the number of automated assembly lines is constant, the resource utilization of automated assembly line sorting systems increases with an increase of daily number of express items. As is shown in Figure 7, when the daily number of express items is between 1000 pieces and 5000 pieces, we can use one automated assembly line. The resource utilization rises 
linearly. Companies need to add an assembly line when the daily number of express items reaches 6000 pieces. At this time, resource utilization falls due to abundant resources. When the daily business volume is between 6000 pieces and 9000 pieces, we use two automated assembly line and the resource utilization rises linearly again.

We selected the least number of resources that can just finish sorting tasks as the number of resources. Therefore, the resource utilization for manual sorting can always reach $95 \%$ or more.

\section{CONCLUSIONS}

This paper discussed the redesign of automated assembly line sorting operation processes with the support of radio frequency identification and reflects the many advantages of using automated assembly line sorting. Meanwhile, since the high disposable fixed costs of introducing an automated assembly line is difficult for small- and medium-sized courier companies, we also proposed a sharing mechanism for sorting systems. We presented sorting system simulation models to compare indexes for manual sorting with those of automated assembly line sorting and as a tool to help companies decide when to use automated assembly line sorting in order to reduce costs and improve sorting efficiency. The results of the simulations show that the average number of express items in the waiting line and the average time spent in the waiting line in an automated assembly line sorting systems are all less than that of manual sorting, which fully demonstrates that an automated assembly line can enhance sorting efficiency and the express item turnover ratio.

The conclusions highlight the importance of automated assembly lines for courier companies. This paper described in detail a redesigned process for sorting systems, and also proposed an important tool to support the redesign of automated assembly line sorting in courier companies. The model indicated that the daily number of express items when using an automated assembly line can have lower costs and resource utilization. Further research can extend the work of this paper by adding prices, profit and cooperative mechanisms into the simulation model. Radio frequency identification technology can also be applied to other logistics process to improve logistics distribution efficiency.

\section{ACKNOWLEDGMENT}

This research is supported by National Natural Science Foundation of China major program (Grant No. 71090404/71090400), National Natural Science Foundation of China (Grant No. 71171029) and Shanghai Leading Academic Discipline Project (Project Number: B310). 


\section{REFERENCES}

[1] J. Ashayeri, and M. Goetschalckx, Classification and design of order picking. Logistic World, p99-106, 1989. http://dx.doi.org/10.1108/eb007469.

[2] G. Marchet, M. Melacini, and S. Perotti, A model for design and performance estimation of pick-and-sort order picking systems. Journal of Manufacturing Technology Management, 22(2), p261-282, 2011. http://dx.doi.org/10.1108/17410381111102252.

[3] J. Drury, Towards more efficient order picking, IMM Monograph No. 1. Cranfield, U.K.: The Institute of Materials Management, 1988.

[4] R. De Koster, T. Le-Duc, and K. Roodbergen, Design and control of warehouse order picking: a literature review. European Journal of Operational Research, 182(2), p481-501, 2007. http:/dx.doi.org/10.1016/j.ejor.2006.07.009.

[5] James C. Chen, Chen-Huan Cheng, Po Tsang B. Huang, Kung-Jen Wang, Chien-Jung Huang, and Ti-Chen Ting, Warehouse management with lean and radio frequency identification application: a case study. The International Journal of Advanced Manufacturing Technology, 69(1-4), p531-542, 2013.

[6] S. Fosso Wamba, L.A. Lefebvre, Y. Bendavid, and É Lefebvre. Exploring the impact of RFID technology and the EPC network on mobile B2B eCommerce: A case study in the retail industry. International Journal of Production Economics, 112(2), p614-629, 2008. http://dx.doi.org/10.1016/j.ijpe.2007.05.010.

[7] S. Fosso Wamba, T.R. Coltman, and K. Michael, Radio frequency identification-enabled warehouse optimization: Lessons from early adopters in the 3PL industry. Paper presented at the International Conference on Information Systems, France, Paris, December 14-17, 2008.

[8] G.Q. Huang, Y.F. Zhang, and P.Y. Jiang, Radio frequency identification-based wireless manufacturing for real-time management of job shop WIP inventories. The International Journal of Advanced Manufacturing Technology, 36(7-8), p752-764, 2008.

[9] R. Bloss, Automation pushes the envelope of postal mail handling efficiency. Assembly Automation, 33(1), p3-7, 2013.

[10] L. Gorney, Queueing theory: A problem solving approach. New York: Petrocelli.Books, 1981.

[11] A. U.S. Guide, Automation, Rockwell, Arena-User's Guide. USA: Alen Bradely, 2007.

[12] A. Teilans, A. Kleins, Y. Merkuryev, and A. Grinbergs. Design of UML models and their simulation using ARENA. WSEAS Transactions on Computer Research, 3(1), p67-73, 2008. 
[13] G.E. Vieira, Ideas for modeling and simulation of supply chains with Arena. Paper presented at the 2004 Winter Simulation Conference, Washington, D.C., U.S.A., December 5-8, 2004. http://dx.doi.org/10.1109/WSC.2004.1371481.

[14] A.P. Iannoni, and R. Morabito, A discrete simulation analysis of a logistics supply system. Transportation Research Part E: Logistics and Transportation Review, 42(3), p191-210, 2006. http://dx.doi.org/10.1016/j.tre.2004.10.002. 